\title{
Trends and predictors of linkage to HIV outpatient care following diagnosis in the era of expanded testing in England, Wales and Northern lreland: Results of a national cohort study
}

\author{
S Croxford (iD ${ }^{1,2}$ F Burns,,$^{2,3}$ A Copas, ${ }^{2} \mathrm{Z} \mathrm{Yin}^{1}$ and V Delpech (DD ${ }^{1}$ \\ ${ }^{1}$ National Infection Service, Public Health England, London, UK, ${ }^{2}$ Institute for Global Health, University College London, \\ London, UK and ${ }^{3}$ Royal Free London NHS Foundation Trust, London, UK \\ Abstract
}

\begin{abstract}
Objectives
We explore trends in linkage to HIV care following diagnosis and investigate the impact of diagnosis setting on linkage in the era of expanded testing.

Methods

All adults (aged $\geq 15$ years) diagnosed with HIV between 2005 and 2014 in England, Wales and Northern Ireland (EWENI) were followed up until the end of 2017. People who died within 1 month of diagnosis were excluded ( $n=1009$ ). Trends in linkage to outpatient care (time to first CD4 count) were examined by sub-population and diagnosis setting. Logistic regression identified predictors of delayed linkage of $>1$ month, $>3$ months and $>1$ year post-diagnosis (2012-2014).

Results

Overall, 97\% (60 250/62 079) of people linked to care; linkage $\leq 1$ month was 75\% (44 291/ 59 312), $\leq 3$ months was 88\% (52 460) and $\leq 1$ year was 95\% (56 319). Median time to link declined from 15 days [interquartile range (IQR): 4-43] in 2005 to 6 (IQR: 0-20) days in 2014 (similar across sub-populations/diagnosis settings). In multivariable analysis, delayed linkage to care was associated with acquiring HIV through injecting drug use, heterosexual contact or other routes compared with sex between men ( $>1$ month/3 months/1 year), being diagnosed in earlier years ( $>1$ month/3 months/1 year) and having a first CD4 $\geq 200$ cells/ $\mu \mathrm{L}(>3$ months/1 year). Diagnosis outside of sexual health clinics, antenatal services and infectious disease units predicted delays of $>1$ month. By 3 months, only diagnosis in 'other' settings (prisons, drug services, community and other medical settings) was significant.

\section{Conclusions}

Linkage to care following HIV diagnosis is relatively timely in EW\&NI. However, non-traditional testing venues should have well-defined referral pathways established to facilitate access to care and treatment.
\end{abstract}

Keywords: adults, HIV infection/diagnosis, HIV infection/epidemiology, patient care, United Kingdom

Accepted 29 December 2020

\footnotetext{
Correspondence: Sara Croxford, National Infection Service, Public Health England, 61 Colindale Avenue, London NW9 5EQ, UK. Tel: +44 020 83277406; e-mail: sara.croxford@phe.gov.uk

This is an open access article under the terms of the Creative Commons Attribution-NonCommercial License, which permits use, distribution and reproduction in any medium, provided the original work is properly cited and is not used for commercial purposes.
}

\section{Introduction}

Evidence from the UK has shown that effective testing strategies are central to the prevention of HIV [1,2]. Over the past decade, in an effort to reduce late diagnosis and undiagnosed infection, there has been a shift in the 
national HIV testing guidelines to promote expanded testing outside of traditional healthcare settings, such as sexual health clinics (SHCs), antenatal services and infectious disease units [3-5]. The offering of testing in non-traditional venues has been shown to be playing an increasingly important role in diagnosing people with HIV [6,7].

It is crucial to ensure that linkage to HIV clinical care following diagnosis is prompt and equitable, regardless of testing venue or test type; delayed initiation of HIV care has implications for both the health of the individual and the public. For those who test positive for HIV, care facilitates timely access to treatment. Rapid initiation of antiretroviral therapy (ART), regardless of CD4 count at diagnosis, has substantial benefits, reducing the risk of serious morbidity and mortality [8]. Prompt linkage to care and treatment also has a public health impact, reducing transmission potential; people adherent to ART and virally suppressed, with an HIV viral load $<200$ copies/mL, cannot transmit the virus to others $[9,10]$. Since 2007, the British HIV Association (BHIVA) has recommended that 'all patients should be assessed by a doctor who provides HIV care within 2 weeks of a positive HIV test result, irrespective of the place of testing' [11].

This study builds on previous work describing trends in HIV diagnosis setting in England, Wales and Northern Ireland (EW\&NI) using national surveillance data [7]. Here, we follow the same cohort to the end of 2017, in order to explore trends in linkage to HIV outpatient care following diagnosis across these settings and identify factors associated with delayed linkage.

\section{Methods}

\section{Data sources and population}

The UK HIV surveillance dataset utilized for these analyses has been described previously [7]. Briefly, data on people newly diagnosed with HIV in the UK are reported to Public Health England (PHE) by laboratories and clinicians across a variety of settings in EW\&NI. Subsequent information on the clinical care of these individuals is submitted by National Health Service (NHS) HIV outpatient services. We analysed data on the cohort of adults (aged $\geq$ 15 years at diagnosis) diagnosed in EW\&NI between 2005 and 2014, followed up until the end of 2017.

Diagnosis setting was grouped into six categories: SHCs, antenatal services, outpatient services (e.g. hepatology, tuberculosis, fertility, haemophilia etc.), inpatient services and accident and emergency (A\&E), infectious disease units (both inpatient and outpatient), general practice (GP) and 'other' (prisons, blood services, drug misuse services, community organizations and non-specified medical settings).

\section{Statistical analyses}

People were considered linked to care if they attended for specialist outpatient HIV care after diagnosis, evidenced by an HIV outpatient clinical record and/or a CD4 count taken before the end of 2017. First CD4 count was used as a proxy for care entry, as CD4 testing is recommended by both the World Health Organization (WHO) and the British HIV Association (BHIVA) as a key baseline assessment for people newly diagnosed with HIV [11-14]. Timeliness of linkage was only able to be measured among those with a first CD4 date reported (proxy of care date), as first attendance date was not collected through surveillance mechanisms until 2015. CD4 count data were included up to 14 days before diagnosis to account for potential errors in date reporting. People were excluded if they died within 1 month of diagnosis.

Among those linked to care with a first CD4 date reported, timeliness of linkage was calculated at 1 month ( $\leq 31$ days), 3 months ( $\leq 91$ days) or 1 year ( $\leq 365$ days) post-diagnosis. Pearson $\chi^{2}$ tests for trend were used to assess changes in the proportion linked to care at the specified intervals over the decade for everyone and for men who have sex with men (MSM), black African men and women and people who inject drugs (PWID) separately (significance level, $P<0.05$ ). MSM and PWID were defined based on the probable route of HIV acquisition.

Logistic regression was used to identify factors associated with delayed linkage to care of more than 1 month, 3 months and 1 year post-diagnosis among those diagnosed in recent years (2012-2014) with a first CD4 date reported. Variables found to be significant in univariable analysis $(P<0.10)$ were included in a backward stepwise model selection process based on $P>0.05$ as a threshold for removal. First CD4 count was considered for inclusion in these models as a proxy for health status at diagnosis.

\section{Results}

\section{Linkage to care overall}

Of the 63088 adults first diagnosed with HIV in EW\&NI between 2005 and 2014, 1009 died within 1 month of diagnosis (Table S1). Overall, 97\% (60 250/62 079) (range: 96-98\%) of people were ever linked to care by the end of 2017, including 938 who were linked to care but had no first CD4 date (Table S1). Those with no HIV 
clinical outpatient record after diagnosis $(n=1829)$ were assumed never linked (Table S1).

Trends in linkage to care

Among the 59312 people who linked to care with a date of entry (CD4 date), 75\% (44 291) were linked to care within 1 month of diagnosis, 88\% (52 460) within 3 months and 95\% (56 319) within 1 year. There were 11035 people linked to care on the day of their diagnosis and these were more likely to be MSM diagnosed in SHCs. Median (IQR) time to linkage declined over the decade from 15 (4-43) days in 2005 to 6 (0-20) days in 2014 (Fig. 1). This trend of decreasing median time to linkage was also seen in the key population subgroups and across diagnosis settings (Fig. S1).

Figure 2 shows trends in linkage to care at specified intervals after diagnosis (1 month, 3 months and 1 year) over time by key population group. Overall, linkage to care within 1 month increased from 69\% (4802/6966) in 2005 to $82 \%(4270 / 5222)$ in $2014(P<0.001)$, within 3 months from 85\% (5932) to 92\% (4814) $(P<0.001)$ and within 1 year from 93\% (6458) to 99\% (5156) $(P<0.001)$. Although linkage to care increased significantly over the decade for almost all population groups (Fig. 2a-c), there were some disparities between groups. At all time intervals, MSM had the highest proportion linked to care and PWID, the lowest. In 2014, linkage for MSM post-diagnosis was 85\% (2424/2841) at 1 month, 93\% (2655) at 3 months and 99\% (2819) at 1 year; these figures for PWID were 70\% (75/107), 84\% (90) and 96\% (103), respectively. By 1 year after diagnosis, the difference in linkage between groups was minimal, aside from PWID (Fig. 2c).

The proportion of people linked to care increased significantly over time across almost all diagnosis settings

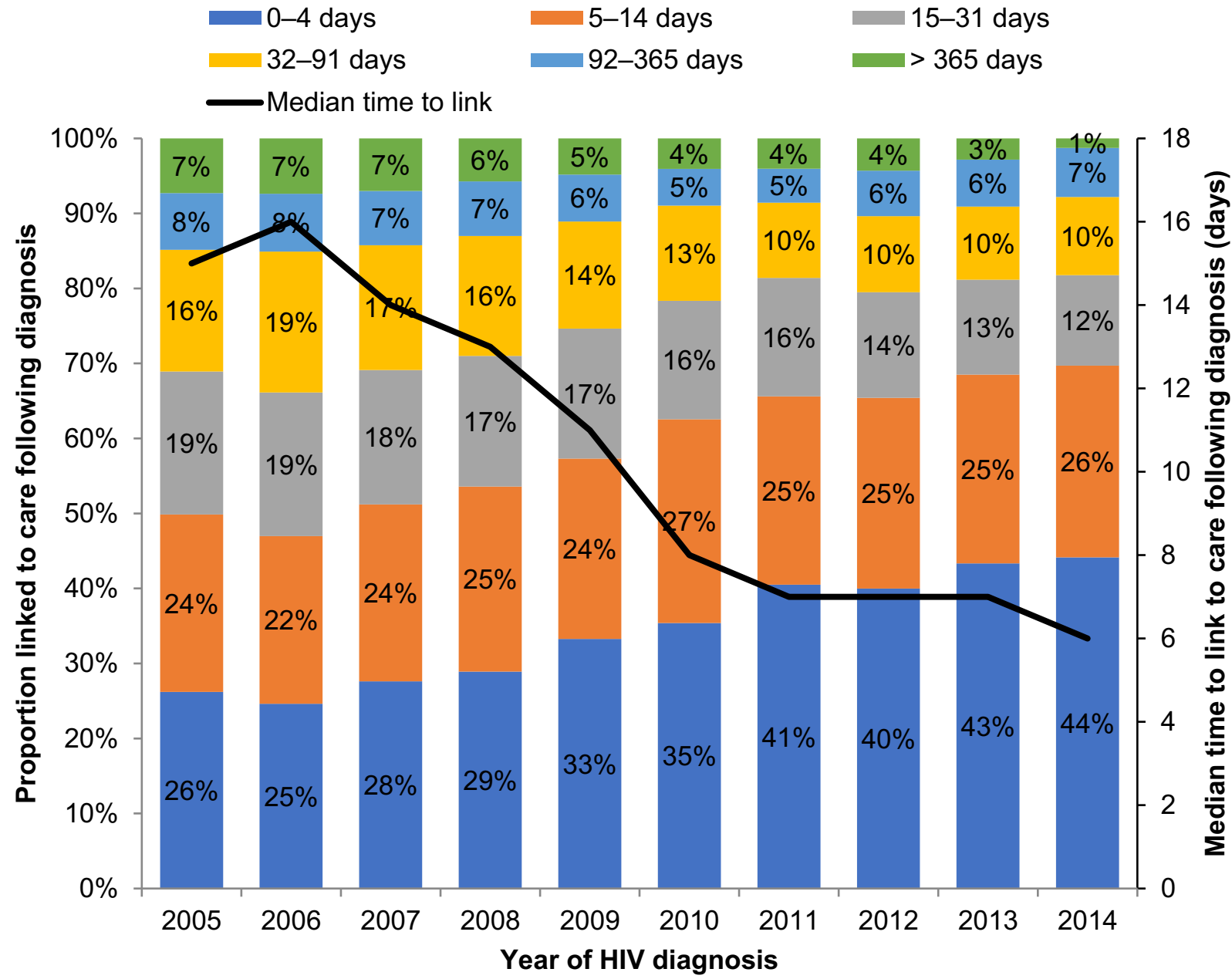

Fig. 1 Time to enter care following HIV diagnosis among people who linked by year: England, Wales and Northern Ireland (EWENNI), 20052014. 

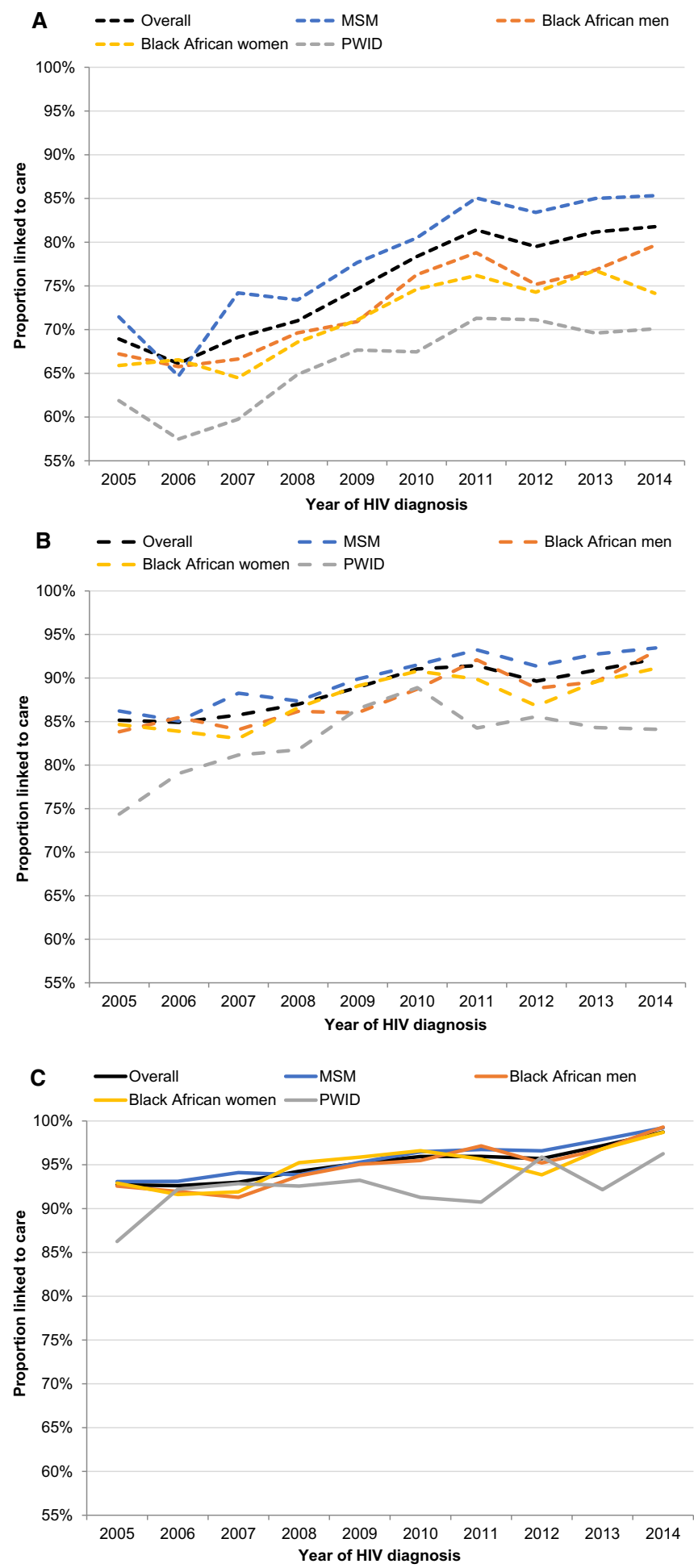

Fig. 2 Linkage to care by population subgroup in England, Wales and Northern Ireland (EWEtNI), 2005-2014, within: (a) 1 month of diagnosis $\left[\chi^{2}\right.$ test for trend: overall, $P<0.001$; men who have sex with men (MSM), $P<0.001$; black African men, $P<0.001$; black African women, $P$ $<0.001$; people who inject drugs (PWID), $P=0.157$ ); (b) 3 months of diagnosis $\left(\chi^{2}\right.$ test for trend: overall, $P<0.001 ;$ MSM, $P<0.001 ;$ black African men, $P<0.001$; black African women, $P<0.001$; PWID, $P=0.085)$; and (c) 1 year of diagnosis $\left(\chi^{2}\right.$ test for trend: overall, $P<0.001$; MSM, $P<0.001$; Black African men, $P<0.001$; Black African women, $P<0.001$; PWID, $P=0.174)$. 
and specified linkage time intervals (Fig. 3), apart from in antenatal services and infectious disease units at 3 months and 1 year. Overall, the proportion linked to care at 1 and 3 months post-diagnosis was highest among people diagnosed with HIV in infectious disease units and SHCs. In 2014, linkage from infectious disease units at these time intervals was 89\% (77/87) and 97\% (84), respectively; in SHCs, linkage at 1 month was $86 \%$ (2784/3228) and at 3 months was 94\% (3038). People diagnosed in other settings had the lowest rates of linkage to care within these time intervals [2014: 75\% (166/ 221) and 90\% (200)]. By 1 year post-diagnosis the difference in linkage across diagnosis settings was minimal (Fig. 3c).

\section{Factors associated with delayed linkage to care}

Multivariable logistic regression analyses were used to explore factors associated with delayed linkage to care post-diagnosis in recent years (2012-2014) of more than 1 month, 3 months and 1 year (Tables 1-3). Neither sex nor age at diagnosis was associated with delays in linkage to care at any time point. Diagnosis year was significant in all three models, with the odds of delayed linkage to care decreasing significantly from 2012 to 2014, indicating improvements in linkage over time. At 1 month, 3 months and 1 year after diagnosis, acquiring HIV through heterosexual contact, IDU and other transmission routes was associated with delays compared with HIV acquisition through sex between men. Ethnicity contributed to the final model of delayed linkage of more than 1 month (Table 1), although no particular ethnic group was at significantly higher odds. However, ethnicity was insignificant in the models for delayed linkage of over 3 months and 1 year (Tables 2 and 3). Conversely, first CD4 count after diagnosis was only a significant predictor of linkage delays of $>3$ months and 1 year, with higher CD4 counts at diagnosis being associated with higher odds of being delayed (Tables 2 and 3).

The relationship between diagnosis setting and linkage to care changed over time from diagnosis. At 1 month, diagnosis in all settings, apart from antenatal services and infectious disease units, had a higher odds of delayed linkage to care compared with diagnosis in SHCs (Table 1). At 3 months, the only setting-specific significant predictor of delayed linkage to care was being diagnosed in 'other' settings, including prisons, drug services, the community and other healthcare settings not specified (Table 2). At 1 year, diagnosis setting was not associated with delayed care entry at all and was not included in the model (Table 3).

\section{Discussion}

This is the first investigation into linkage to HIV care following diagnosis in EWENI. Encouragingly, 97\% of people diagnosed with HIV between 2005 and 2014 were ever linked to care after diagnosis; among those who were linked, timeliness improved over the years, with $82 \%$ of people being linked to care within 1 month, 92\% within 3 months and 99\% within 1 year in 2014. However, despite overall improvements, some disparities were evident across key population groups, with heterosexuals and PWID taking longer to link than MSM. Diagnosis setting played a large role in determining whether linkage occurred within 1 month of diagnosis; however, setting had limited impact on the time to link subsequently.

In the 2013 Standards for Care for People Living with HIV, BHIVA set out the first measurable and auditable patient outcomes, including one specific to linkage to care: the proportion of people newly diagnosed with HIV with a CD4 count result within 1 month of their HIV diagnosis (target $>95 \%$ ) [13,14]. In 2014, linkage to care within 1 month was only 82\%, much below the 95\% target set in the standards; the latest published national data on linkage from PHE show this figure had only increased to $89 \%$ by 2018 [15]. Recent BHIVA audit data on the clinical pathways of a sample of those newly diagnosed in 2018/2019 in the UK found that only 83\% were seen by a specialist clinician within 4 weeks of receiving their result [16]. Despite the targets being applicable 'irrespective of the place of testing', our findings highlight significant disparities in linkage to care in the month following diagnosis by HIV test setting, with delayed linkage associated with being diagnosed in non-traditional settings, outside of SHCs, antenatal services and infectious disease units. Reassuringly, these disparities had largely disappeared by 3 months after diagnosis and there was no evidence of an association between diagnosis setting and time to linkage by 1 year. Linkage may have been particularly timely from SHCs, as the majority of SHCs and HIV clinics are co-located in the UK [17]. While diagnosis setting has been documented as a known predictor of delayed linkage to care in the USA, particularly in nonmedical settings [18-21], this is the first study to characterize the time-dependent relationship between diagnosis setting and time to linkage in a publicly funded national health system, free at the point of use.

The offering of testing in non-traditional venues plays an important role in diagnosing people with HIV; in 2014, 27\% of people were diagnosed outside of SHCs, antenatal services or infectious disease units [7]. Despite the risk that people diagnosed in non-traditional settings will take longer to be linked into HIV care, expanded 

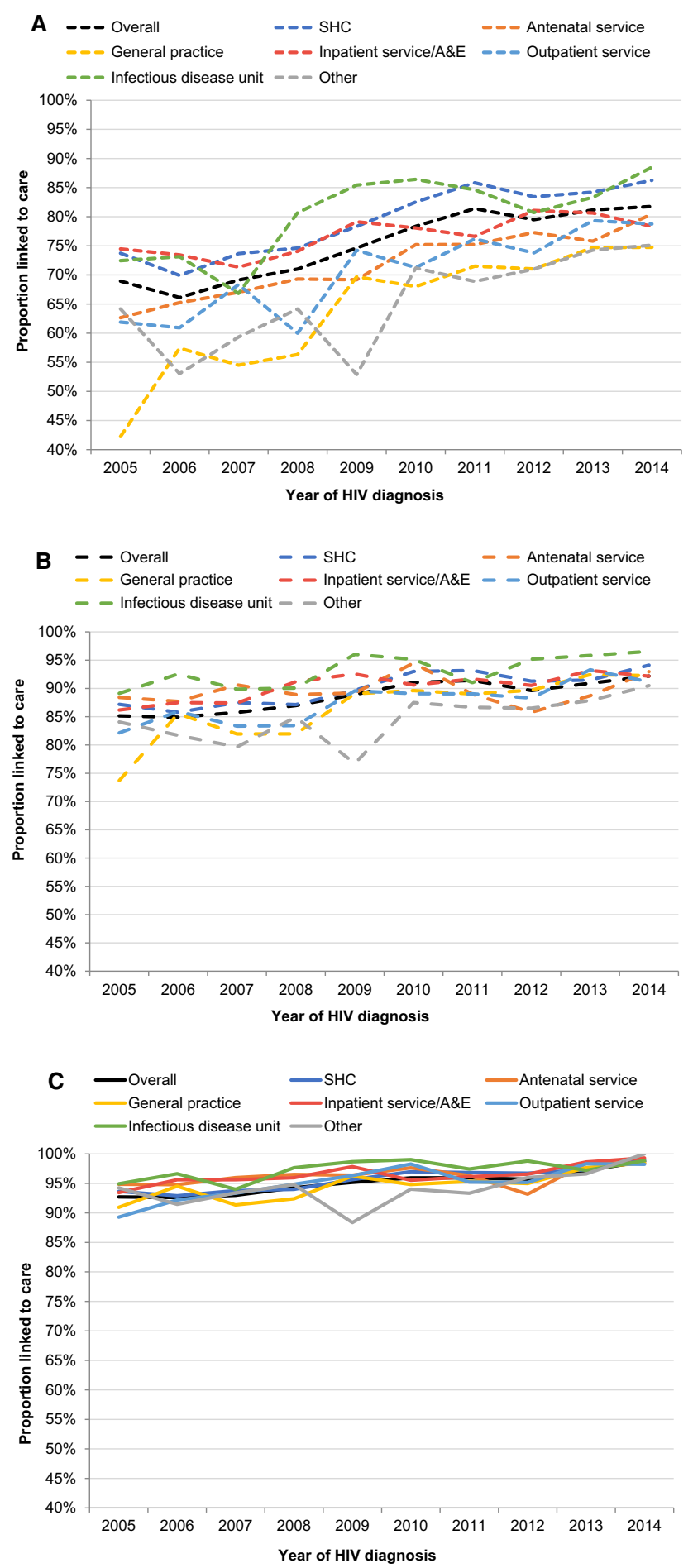

Fig. 3 Linkage to care by diagnosis setting in England, Wales and Northern Ireland (EWENI), 2005-2014, within: (a) 1 month of diagnosis $\left[\chi^{2}\right.$ test for trend: overall, $P<0.001$; sexual health clinic (SHC), $P<0.001$; antenatal, $P<0.001$; general practitioner (GP), $P<0.001$; inpatient/ ActE, $P<0.001$; outpatient, $P=0.014$; infectious disease, $P<0.001$; other, $P<0.001)$; (b) 3 months of diagnosis $\left(\chi^{2}\right.$ test for trend: overall, $P$ $<0.001$; SHC, $P<0.001$; antenatal, $P=0.137$; GP, $P<0.001$; inpatient $/ A$ AtE, $P=0.004$; outpatient, $P=0.022$; infectious disease, $P=0.121$; other, $P=0.007$ ); and (c) 1 year of diagnosis ( $\chi^{2}$ test for trend: overall, $P<0.001$; SHC, $P<0.001$; antenatal, $P=0.180$; GP, $P<0.001$; inpatient/ActE, $P<0.001$; outpatient, $P=0.001$; infectious disease, $P=0.135$; other, $P<0.001$ ). 
Table 1 Factors associated with entry into care being delayed by more than 1 month after HIV diagnosis: England, Wales and Northern Ireland, 2012-2014

\begin{tabular}{|c|c|c|c|c|c|c|c|c|}
\hline \multirow[b]{2}{*}{ Variables } & \multicolumn{2}{|c|}{$\begin{array}{l}\text { Linkage to care } \\
>1 \text { month after } \\
\text { diagnosis }\end{array}$} & \multicolumn{3}{|c|}{ Unadjusted odds ratio (OR) } & \multicolumn{3}{|c|}{ Adjusted odds ratio (aOR) } \\
\hline & $n$ & $\%$ & OR & $95 \% \mathrm{Cl}$ & $P$-value* & $\mathrm{aOR}$ & $95 \% \mathrm{Cl}$ & $P$-value ${ }^{\dagger}$ \\
\hline \multicolumn{9}{|l|}{$\operatorname{Sex}^{\ddagger}$} \\
\hline Men & 2125 & $18 \%$ & 1.00 & - & - & & & \\
\hline Women & 938 & $24 \%$ & 1.45 & $1.33-1.58$ & $<0.001$ & & & \\
\hline \multicolumn{9}{|l|}{ Age at diagnosis (years) ${ }^{\ddagger}$} \\
\hline $15-24$ & 383 & $20 \%$ & 1.00 & - & - & & & \\
\hline $25-34$ & 941 & $18 \%$ & 0.88 & $0.77-1.00$ & & & & \\
\hline $35-49$ & 1,251 & $20 \%$ & 1.02 & $0.90-1.16$ & & & & \\
\hline$\geq 50$ & 488 & $20 \%$ & 1.02 & $0.88-1.19$ & 0.010 & & & \\
\hline \multicolumn{9}{|l|}{ Diagnosis year } \\
\hline 2012 & 1122 & $21 \%$ & 1.00 & - & - & 1.00 & - & - \\
\hline 2013 & 989 & $19 \%$ & 0.90 & $0.82-0.99$ & & 0.93 & $0.83-1.04$ & \\
\hline 2014 & 952 & $18 \%$ & 0.86 & $0.79-0.95$ & 0.008 & 0.81 & $0.73-0.91$ & $<0.001$ \\
\hline \multicolumn{9}{|l|}{ Diagnosis setting } \\
\hline Sexual health clinic & 1437 & $15 \%$ & 1.00 & - & - & 1.00 & - & - \\
\hline Antenatal service & 95 & $22 \%$ & 1.57 & $1.24-1.99$ & & 1.17 & $0.91-1.50$ & \\
\hline General practice & 289 & $26 \%$ & 1.65 & $1.36-1.99$ & & 1.74 & $1.50-2.03$ & \\
\hline Inpatient service/A\&tE & 267 & $20 \%$ & 1.37 & $1.19-1.59$ & & 1.22 & $1.04-1.42$ & \\
\hline Outpatient service & 150 & $23 \%$ & 1.99 & $1.72-2.30$ & & 1.33 & $1.09-1.63$ & \\
\hline Infectious disease unit & 38 & $16 \%$ & 1.03 & $0.72-1.46$ & & 0.95 & $0.67-1.36$ & \\
\hline Other & 166 & $26 \%$ & 1.99 & $1.65-2.40$ & $<0.001$ & 1.82 & $1.50-2.21$ & $<0.001$ \\
\hline \multicolumn{9}{|l|}{ Exposure } \\
\hline Sex between men & 1314 & $15 \%$ & 1.00 & - & - & 1.00 & - & - \\
\hline Heterosexual contact & 1444 & $23 \%$ & 1.62 & $1.49-1.76$ & & 1.41 & $1.26-1.59$ & \\
\hline Injecting drug use & 91 & $30 \%$ & 2.32 & $1.80-2.99$ & & 2.17 & $1.64-2.89$ & \\
\hline Other & 67 & $32 \%$ & 2.55 & $1.90-3.43$ & $<0.001$ & 2.16 & $1.51-3.11$ & $<0.001$ \\
\hline \multicolumn{9}{|l|}{ Ethnicity } \\
\hline White & 1602 & $17 \%$ & 1.00 & - & - & 1.00 & - & - \\
\hline Black African & 877 & $24 \%$ & 1.51 & $1.38-1.66$ & & 1.11 & $0.98-1.27$ & \\
\hline Black Caribbean & 87 & $18 \%$ & 1.08 & $0.85-1.37$ & & 0.85 & $0.64-1.12$ & \\
\hline Asian & 160 & $17 \%$ & 1.00 & $0.83-1.19$ & & 0.82 & $0.66-1.01$ & \\
\hline Other & 228 & $18 \%$ & 1.04 & $0.89-1.21$ & $<0.001$ & 0.93 & $0.78-1.12$ & 0.032 \\
\hline \multicolumn{9}{|l|}{ First CD4 count (cells/ $\mu \mathrm{L}$ ) } \\
\hline$<200$ & 701 & $19 \%$ & 1.00 & - & - & & & \\
\hline $200-349$ & 626 & $21 \%$ & 1.13 & $1.00-1.27$ & & & & \\
\hline $350-499$ & 645 & $19 \%$ & 1.01 & $0.90-1.14$ & & & & \\
\hline$\geq 500$ & 1091 & $19 \%$ & 1.01 & $0.91-1.12$ & 0.151 & & & \\
\hline
\end{tabular}

testing can reach people who may not present at SHCs or other health services and who have not tested previously [22]. Diagnosing these individuals ultimately reduces the time of infectivity. These findings highlight the need for all testing venues to have well-defined, immediate referral pathways in place to facilitate equitable access to HIV specialist care and treatment following a positive HIV test result. This is especially relevant with the introduction of rapid ART initiation and scale-up of HIV self-sampling and self-testing in the UK in recent years [23-25].

Positively, there are no direct legal and regulatory barriers to accessing HIV care and treatment in the UK, as specialist HIV services are cost-free for all, including both documented and undocumented migrants [26,27].
However, there are a variety of reasons why some people take longer to link to HIV care services after diagnosis than others, reflected in the demographic disparities presented here. Delays to initiating care may be a result of personal barriers, such as a lack of HIV knowledge, perceived and experienced stigma and discrimination, fear of disclosure, diagnosis, medication, incarceration and deportation, complex co-morbidities (e.g. hepatitis B or C co-infection, depression, psychosis), a lack of family or social support and addiction [28-32]. In addition, people may not have the personal resources to access care; they may be unemployed with limited personal finances and housing instability or be employed but have time constraints [28,29,31]. Migrants may additionally have a 
Table 2 Factors associated with entry into care being delayed by more than 3 months after HIV diagnosis: England, Wales and Northern Ireland, 2012-2014

\begin{tabular}{|c|c|c|c|c|c|c|c|c|}
\hline \multirow[b]{2}{*}{ Variables } & \multicolumn{2}{|c|}{$\begin{array}{l}\text { Linkage to care } \\
>3 \text { months after } \\
\text { diagnosis }\end{array}$} & \multicolumn{3}{|c|}{ Unadjusted odds ratio (OR) } & \multicolumn{3}{|c|}{ Adjusted odds ratio (aOR) } \\
\hline & $n$ & $\%$ & OR & $95 \% \mathrm{Cl}$ & $P$-value* & $\mathrm{aOR}$ & $95 \% \mathrm{Cl}$ & $P$-value \\
\hline \multicolumn{9}{|l|}{$\operatorname{Sex}^{\ddagger}$} \\
\hline Men & 1015 & $8 \%$ & 1.00 & - & - & & & \\
\hline Women & 437 & $11 \%$ & 1.35 & $1.20-1.52$ & $<0.001$ & & & . \\
\hline \multicolumn{9}{|l|}{ Age at diagnosis (years) } \\
\hline $15-24$ & 196 & $10 \%$ & 1.00 & - & - & & & \\
\hline $25-34$ & 495 & $9 \%$ & 0.92 & $0.77-1.09$ & & & & \\
\hline $35-49$ & 559 & $9 \%$ & 0.88 & $0.74-1.04$ & & & & \\
\hline$\geq 50$ & 202 & $8 \%$ & 0.81 & $0.66-0.99$ & 0.194 & & & \\
\hline \multicolumn{9}{|l|}{ Diagnosis year } \\
\hline 2012 & 567 & $10 \%$ & 1.00 & - & - & 1.00 & - & - \\
\hline 2013 & 477 & $9 \%$ & 0.86 & $0.76-0.98$ & & 0.86 & $0.74-1.00$ & \\
\hline 2014 & 408 & $8 \%$ & 0.73 & $0.64-0.84$ & $<0.001$ & 0.62 & $0.53-0.73$ & $<0.001$ \\
\hline \multicolumn{9}{|l|}{ Diagnosis setting } \\
\hline Sexual health clinic & 719 & $8 \%$ & 1.00 & - & - & 1.00 & - & - \\
\hline Antenatal service & 48 & $11 \%$ & 1.52 & $1.11-2.07$ & & 1.15 & $0.82-1.60$ & \\
\hline General practice & 93 & $9 \%$ & 1.12 & $0.89-1.40$ & & 1.02 & $0.80-1.29$ & \\
\hline Inpatient service/A\&tE & 108 & $8 \%$ & 1.06 & $0.86-1.30$ & & 1.12 & $0.89-1.42$ & \\
\hline Outpatient service & 61 & $9 \%$ & 1.24 & $0.94-1.63$ & & 1.00 & $0.73-1.36$ & \\
\hline Infectious disease unit & 10 & $4 \%$ & 0.52 & $0.27-0.98$ & & 0.53 & $0.28-1.00$ & \\
\hline Other & 73 & $12 \%$ & 1.59 & $1.23-2.05$ & $<0.001$ & 1.49 & $1.14-1.95$ & 0.026 \\
\hline \multicolumn{9}{|l|}{ Exposure } \\
\hline Sex between men & 637 & $7 \%$ & 1.00 & - & - & 1.00 & - & - \\
\hline Heterosexual contact & 636 & $10 \%$ & 1.38 & $1.23-1.55$ & & 1.53 & $1.33-1.76$ & \\
\hline Injecting drug use & 47 & $15 \%$ & 2.25 & $1.63-3.10$ & & 2.83 & $1.98-4.04$ & \\
\hline Other & 39 & $18 \%$ & 2.81 & $1.96-4.01$ & $<0.001$ & 3.70 & $2.46-5.54$ & $<0.001$ \\
\hline \multicolumn{9}{|l|}{ Ethnicity ${ }^{\ddagger}$} \\
\hline White & 775 & $8 \%$ & 1.00 & - & - & & & \\
\hline Black African & 382 & $11 \%$ & 1.28 & $1.13-1.46$ & & & & \\
\hline Black Caribbean & 32 & $7 \%$ & 0.79 & $0.55-1.14$ & & & & \\
\hline Asian & 86 & $9 \%$ & 1.12 & $0.88-1.41$ & & & & \\
\hline Other & 113 & $9 \%$ & 1.07 & $0.87-1.31$ & 0.002 & & & . \\
\hline \multicolumn{9}{|l|}{ First CD4 count (cells/ $\mu \mathrm{L}$ ) } \\
\hline$<200$ & 253 & $7 \%$ & 1.00 & - & - & 1.00 & - & - \\
\hline 200-349 & 299 & $10 \%$ & 1.51 & $1.27-1.80$ & & 1.53 & $1.23-1.88$ & \\
\hline $350-499$ & 327 & $10 \%$ & 1.46 & $1.23-1.74$ & & 1.68 & $1.36-2.07$ & \\
\hline$\geq 500$ & 573 & $10 \%$ & 1.52 & $1.30-1.77$ & $<0.001$ & 1.80 & $1.48-2.19$ & $<0.001$ \\
\hline
\end{tabular}

limited understanding of the healthcare system and face language barriers [29,30]. PWID can face a variety of challenges that affect their use of any medical services, including homelessness, psycho-social instability and unemployment [32]. Feeling well is a known predictor of postponing access to medical care, which may explain why delayed linkage to care was associated with higher CD4 counts in regression analyses [33]. Qualitative research is needed to truly understand the linkage process among people newly diagnosed with HIV across different settings, as the evidence on the barriers and facilitators to accessing HIV care services in the UK is limited.

These analyses make use of high-quality data from a well-established national HIV cohort, where people are able to be followed longitudinally from HIV diagnosis. Nevertheless, there are a number of limitations to these analyses. Coding of the diagnosis setting variable meant 'other' settings were not able to be described in more detail and linkage to care following HIV diagnosis in the community and by HIV self-sampling and self-testing was not able to be explored. First CD4 count date was chosen as a proxy for care entry date because of the data available; date of attendance was not captured routinely as part of HIV surveillance until 2015. One limitation of the use of CD4 is that time to linkage may have been underestimated for those who had a CD4 test carried out using their diagnosis blood sample, which is known to happen anecdotally in the UK, particularly for 
Table 3 Factors associated with entry into care being delayed by more than 1 year after HIV diagnosis: England, Wales and Northern Ireland, 2012-2014

\begin{tabular}{|c|c|c|c|c|c|c|c|c|}
\hline \multirow[b]{2}{*}{ Variables } & \multicolumn{2}{|c|}{$\begin{array}{l}\text { Linkage to care } \\
>1 \text { year after } \\
\text { diagnosis }\end{array}$} & \multicolumn{3}{|c|}{ Unadjusted odds ratio (OR) } & \multicolumn{3}{|c|}{ Adjusted odds ratio (aOR) } \\
\hline & $n$ & $\%$ & $\mathrm{OR}$ & $95 \% \mathrm{Cl}$ & $P$-value* & $\mathrm{aOR}$ & $95 \% \mathrm{Cl}$ & $P$-value ${ }^{\dagger}$ \\
\hline \multicolumn{9}{|l|}{ Sex $x^{*}$} \\
\hline Men & 296 & $2 \%$ & 1.00 & - & - & & & \\
\hline Women & 153 & $4 \%$ & 1.60 & $1.31-1.95$ & $<0.001$ & & & \\
\hline \multicolumn{9}{|l|}{ Age at diagnosis (years) } \\
\hline $15-24$ & 54 & $3 \%$ & 1.00 & - & - & & & \\
\hline $25-34$ & 157 & $3 \%$ & 1.07 & $0.78-1.46$ & & & & \\
\hline $35-49$ & 184 & $3 \%$ & 1.06 & $0.78-1.45$ & & & & \\
\hline$\geq 50$ & 54 & $2 \%$ & 0.79 & $0.54-1.16$ & 0.262 & & & \\
\hline \multicolumn{9}{|l|}{ Diagnosis year } \\
\hline 2012 & 235 & $4 \%$ & 1.00 & - & - & 1.00 & - & - \\
\hline 2013 & 148 & $3 \%$ & 0.65 & $0.52-0.80$ & & 0.61 & $0.49-0.76$ & \\
\hline 2014 & 66 & $1 \%$ & 0.29 & $0.22-0.38$ & $<0.001$ & 0.22 & $0.16-0.30$ & $<0.001$ \\
\hline \multicolumn{9}{|l|}{ Diagnosis setting } \\
\hline Sexual health clinic & 216 & $2 \%$ & 1.00 & - & - & & & \\
\hline Antenatal service & 16 & $4 \%$ & 1.65 & $0.98-2.76$ & & & & \\
\hline General practice & 32 & $3 \%$ & 1.28 & $0.88-1.87$ & & & & \\
\hline Inpatient service/ActE & 25 & $2 \%$ & 0.81 & $0.53-1.23$ & & & & \\
\hline Outpatient service & 19 & $3 \%$ & 1.27 & $0.79-2.04$ & & & & \\
\hline Infectious disease unit & 4 & $2 \%$ & 0.71 & $0.26-1.93$ & & & & \\
\hline Other & 15 & $2 \%$ & 1.04 & $0.61-1.76$ & 0.245 & & & \\
\hline \multicolumn{9}{|l|}{ Exposure } \\
\hline Sex between men & 179 & $2 \%$ & 1.00 & - & - & 1.00 & - & - \\
\hline Heterosexual contact & 206 & $3 \%$ & 1.57 & $1.28-1.92$ & & 1.76 & $1.42-2.17$ & \\
\hline Injecting drug use & 16 & $5 \%$ & 2.57 & $1.52-4.35$ & & 3.07 & $1.80-5.23$ & \\
\hline Other & 13 & $6 \%$ & 3.06 & $1.71-5.47$ & $<0.001$ & 3.77 & $2.09-6.79$ & $<0.001$ \\
\hline \multicolumn{9}{|l|}{ Ethnicity } \\
\hline White & 217 & $2 \%$ & 1.00 & - & - & & & \\
\hline Black African & 128 & $4 \%$ & 1.52 & $1.21-1.89$ & & & & \\
\hline Black Caribbean & 13 & $3 \%$ & 1.18 & $0.67-2.07$ & & & & \\
\hline Asian & 28 & $3 \%$ & 1.30 & $0.87-1.93$ & & & & \\
\hline Other & 31 & $2 \%$ & 1.04 & $0.71-1.52$ & 0.006 & & & \\
\hline \multicolumn{9}{|l|}{ First CD4 count (cells $/ \mu \mathrm{L}$ ) } \\
\hline$<200$ & 79 & $2 \%$ & 1.00 & - & - & 1.00 & - & - \\
\hline $200-349$ & 79 & $3 \%$ & 1.24 & $0.91-1.70$ & & 1.40 & $1.00-1.96$ & \\
\hline $350-499$ & 97 & $3 \%$ & 1.36 & $1.00-1.83$ & & 1.75 & $1.27-2.41$ & \\
\hline$\geq 500$ & 194 & $3 \%$ & 1.61 & $1.23-2.10$ & 0.004 & 2.13 & $1.60-2.85$ & $<0.001$ \\
\hline
\end{tabular}

people diagnosed in clinics with integrated sexual health and HIV services. Regardless, the use of CD4 count date is a well-established proxy of care entry [34]. First CD4 count at care entry was included and adjusted for in regression modelling as a proxy for health status at diagnosis, which was not directly collected. This may have introduced bias when used to predict time to linkage, as CD4 count at care entry is partially caused by the time since diagnosis (reverse causality). However, it was used to represent an important confounder, as delayed linkage has been found to be associated with feeling and/or being well [33].

There were 1829 people with no HIV outpatient clinical record after diagnosis by the end of 2017 (Table S1). In these analyses, these individuals were assumed to be not linked in the calculation of the proportion ever linked. However, HIV surveillance data from the UK are longitudinal and comprehensive and as the vast majority $(n=1784)$ had neither a clinical record nor report of death, it is likely that many may have left the country. A third of these individuals were of black African ethnicity and a quarter were born outside of the UK. For the remainder, all other descriptive data fields were highly incomplete (ethnicity: 43\% missing, region of birth: 67\% missing, HIV exposure: 47\% missing). As HIV testing is free, confidential and anonymous in SHCs across the UK [4], these may also be people who tested under a false name that cannot be merged with their other patient records. Maintaining provision of anonymous HIV testing is 
particularly important as evidence suggests that individuals who test anonymously test earlier in the course of their HIV infection [35]. If these 1784 people were excluded from the calculation of the proportion ever linked, overall linkage would have been $>99 \%$. There were a small number of people $(n=45)$ who died more than 1 month after diagnosis but who were never linked, potentially representing a missed opportunity for intervention.

People who died within 1 month of diagnosis $(n=1009)$ were excluded from linkage analyses regardless of whether they linked to care prior to death ( $n=390$ linked before death). This is because they represent a group of people who were most likely very ill at diagnosis. Although inpatient specialist care may not have been sought, ill patients would be less likely to link to outpatient care. HIV surveillance in the UK captures diagnoses related to inpatient services but not inpatient care attendances (data reported from HIV outpatient services only). This assumption of heightened illness is supported by data on where these patients were diagnosed, showing a higher proportion being diagnosed in inpatient services/A\&tE (21\%) and much lower CD4 counts where available $(88 \%$ had a CD4 count of $<200$ cells $/ \mu \mathrm{L}$ ) (Table $\mathrm{S} 1$ ). There was no impact on the time to linkage figures or the predictors of delayed linkage identified in regression modelling when these individuals were included in sensitivity analyses.

Our findings indicate that linkage to care following diagnosis has improved over the decade and, overall, is prompt. There were some disparities in the timeliness of linkage to care, particularly by diagnosis setting. Not only must all testing venues have established referral pathways in place for people who test positive, but HIV specialist services must also be designed and delivered to maximize opportunities for people who are newly diagnosed to access and engage in care. HIV services should be aware of and linked to local testing services applying a systemwide, integrated approach to patient management. Further research is needed to identify which setting-specific interventions are being implemented in the UK and whether they are effective at improving linkage to specialist care.

\section{Acknowledgements}

Conflict of interest: The authors have no conflicts of interests to declare.

Financial disclosure: None.

\section{Author contributions}

All authors contributed to the design of the study and interpretation of the data, commented on the manuscript and approved the final draft. SC wrote the manuscript, incorporated author comments and was responsible for submission. AC and ZY had input to the methodology and provided statistical expertise. FB and VD contributed important intellectual content to the discussion and conclusions.

\section{References}

1 Brown AE, Mohammed H, Ogaz D et al. Fall in new HIV diagnoses among men who have sex with men (MSM) at selected London sexual health clinics since early 2015: testing or treatment or pre-exposure prophylaxis (PrEP)? Euro Surveill 2017; 22 (25): 30553.

2 Brown AE, Nash S, Connor N et al. Towards elimination of HIV transmission, AIDS and HIV-related deaths in the UK. HIV Med 2018; 19 (8): 505-512.

3 British HIV Association, British Association for STI and HIV, British Infection Society. Guidelines for HIV testing 2008. London, BHIVA, BASHH, BIS, 2008.

4 National Institute of Health and Care Excellence. HIV testing: increasing uptake among people who may have undiagnosed HIV. London, NICE, 2016.

5 National Institute of Health and Care Excellence. HIV testing: encouraging uptake. London, NICE, 2017.

6 Cieply L, Collins S, Penman C, Mandal S, Lattimore S. Trends in HIV testing outside of traditional settings in England. International AIDS Society Conference. Vancouver, July 2015.

7 Croxford S, Yin Z, Kall M et al. Where do we diagnose HIV infection? Monitoring new diagnoses made in nontraditional settings in England, Wales and Northern Ireland. HIV Med 2018; 19 (7): 465-474.

8 Lundgren JD, Babiker AG, Gordin F et al. Initiation of antiretroviral therapy in early asymptomatic HIV infection. $N$ Engl J Med 2015; 373 (9): 795-807.

9 Cohen MS, Chen YQ, McCauley M, et al. Antiretroviral therapy for the prevention of HIV-1 transmission. $N$ Engl $J$ Med 2016; 375 (9): 830-839.

10 Rodger AJ, Cambiano V, Bruun T et al. Risk of HIV transmission through condomless sex in serodifferent gay couples with the HIV-positive partner taking suppressive antiretroviral therapy (PARTNER): final results of a multicentre, prospective, observational study. Lancet 2019; 393 (10189): 2428-2438.

11 British HIV Association. Standards for HIV clinical care. London, BHIVA, 2007.

12 World Health Organization. Patient monitoring guidelines for HIV care and antiretroviral therapy. Geneva, WHO, 2006.

13 British HIV Association. Standards of care for people living with HIV 2013. London, BHIVA, 2012.

14 British HIV Association. Standards of care for people living with HIV 2018. London, BHIVA, 2018. 
15 0'Halloran C, Sun S, Nash S et al. HIV in the United Kingdom: towards zero HIV transmissions by 2030. London, Public Health England, 2019.

16 Kaide E, Curtis H, Freedman A et al. A national audit of the management pathways for new HIV diagnoses. Int J STD AIDS 2020. In press.

17 National AIDS Trust. HIV in the future NHS. London, NAT, 2016.

18 Jenness SM, Myers JE, Neaigus A, Lulek J, Navejas M, RajSingh S. Delayed entry into HIV medical care after HIV diagnosis: risk factors and research methods. AIDS Care 2012; 24 (10): 1240-1248.

19 Torian LV, Wiewel EW, Liu KL, Sackoff JE, Frieden TR. Risk factors for delayed initiation of medical care after diagnosis of human immunodeficiency virus. Arch Intern Med 2008; 168 (11): 1181-1187.

20 Bamford LP, Ehrenkranz PD, Eberhart MG, Shpaner M, Brady KA. Factors associated with delayed entry into primary HIV medical care after HIV diagnosis. AIDS 2010; 24 (6): 928930.

21 Yehia BR, Ketner E, Momplaisir F et al. Location of HIV diagnosis impacts linkage to medical care. J Acquir Immune Defic Syndr 2015; 68 (3): 304-309.

22 Croxford S, Tavoschi L, Sullivan AK et al. HIV testing strategies outside of health care settings in the European Union (EU)/European Economic Area (EEA): a systematic review to inform European Centre for Disease Prevention and Control guidance. HIV Med. 2020; 21 (3): 142-162.

23 Brady M, Carpenter G, Bard B. Self-testing for HIV: initial experience of the UK's first kit. HIV Med 2016; 17 (S1): 9.

24 NHS England. Clinical commissioning policy: immediate antiretroviral therapy for treatment of HIV-1 in adults and adolescents. London, NHS England, 2018.

25 Public Health England. National HIV self-sampling service: November 2017 to October 2018. London, PHE, 2019.

26 Power L. OptTEST case study 1: getting equal and free HIV treatment for undocumented migrants in England [online] 2017 [cited 18/03/2020]. Available at http://www.opttest.eu/ Portals/0/WP7\%20docs/OptTEST\%20Case\%20Study\%201_ Undocumented\%20migrants\%20UK.pdf (accessed 04 November 2020).

27 National AIDS Trust. Who has to pay? How NHS overseas visitor charges apply to migrants and asylum seekers in England. London, NAT, 2018.
28 Burns F, Fenton KA. Access to HIV care among migrant Africans in Britain. What are the issues? Psychol Health Med 2006; 11 (1): 117-125.

29 Burns FM, Imrie JY, Nazroo J, Johnson AM, Fenton KA. Why the(y) wait? Key informant understandings of factors contributing to late presentation and poor utilization of HIV health and social care services by African migrants in Britain. AIDS Care 2007; 19 (1): 102-108.

30 Shangase P, Egbe CO. Barriers to accessing HIV services for black African communities in Cambridgeshire, the United Kingdom. J Community Health 2015; 40 (1): 20-26.

31 Erwin J, Morgan M, Britten N, Gray K, Peters B. Pathways to HIV testing and care by black African and white patients in London. Sex Transm Infect 2002; 78 (1): 37-39.

32 Neale J, Tompkins C, Sheard L. Barriers to accessing generic health and social care services: a qualitative study of injecting drug users. Health Soc Care Community 2008; 16 (2): 147-154.

33 Neduzhko 0, Postnov 0, Perehinets I et al. Factors associated with delayed enrollment in HIV medical care among HIVpositive individuals in Odessa Region, Ukraine. J Int Assoc Provid AIDS Care 2017; 16 (2): 168-173.

34 Zetola NM, Bernstein K, Ahrens K et al. Using surveillance data to monitor entry into care of newly diagnosed HIVinfected persons: San Francisco, 2006-2007. BMC Public Health 2009; 9: 17.

35 Fakoya I, Evans A, Baio G, Burns F, Morris S, Hart G. Review of effectiveness and cost effectiveness: Increasing the uptake of HIV testing to reduce undiagnosed infection and prevent transmission among black African communities living in England. London, National Institute for Health and Care Excellence, 2010.

\section{Supporting Information}

Additional supporting information may be found online in the Supporting Information section at the end of the article.

Table S1. Characteristics of adults excluded from analysis by exclusion criteria: EWENI, 2005-2014.

Figure S1. Median time to link to care in days by (a) population subgroup and (b) diagnosis setting: EWEtNI, 2005-2014. 